\section{artelogie}

\section{Artelogie}

Recherche sur les arts, le patrimoine et la littérature de l'Amérique latine

$10 \mid 2017$

Après le paysage : l'art, l'inscription et la représentation de la nature en Amérique latine aujourd'hui

\title{
Paisaje en las Américas. Pinturas desde la Tierra del Fuego al Ártico de Peter John Brownlee, Valérica Piccoli, Georgiana Uhlyarik
}

\section{Catalina Valdés}

\section{(2) OpenEdition \\ Journals}

Edición electrónica

URL: http://journals.openedition.org/artelogie/932

DOI: $10.4000 /$ artelogie.932

ISSN: 2115-6395

Editor

Association ESCAL

Referencia electrónica

Catalina Valdés, «Paisaje en las Américas. Pinturas desde la Tierra del Fuego al Ártico de Peter John Brownlee, Valérica Piccoli, Georgiana Uhlyarik », Artelogie [En línea], 10 | 2017, Publicado el 05 abril 2017, consultado el 23 septiembre 2020. URL : http://journals.openedition.org/artelogie/932 ; DOI : https://doi.org/10.4000/artelogie.932

Este documento fue generado automáticamente el 23 septiembre 2020

Association ESCAL 


\title{
Paisaje en las Américas. Pinturas desde la Tierra del Fuego al Ártico de Peter John Brownlee, Valérica Piccoli, Georgiana Uhlyarik
}

\author{
Catalina Valdés
}

\section{REFERENCIA}

Peter John Brownlee, Valérica Piccoli, Georgiana Uhlyarik, Paisaje en las Américas.

Pinturas desde la Tierra del Fuego al Ártico, Toronto, Art Gallery of Ontario, Pinacoteca do Estado de São Paulo, Terra Foundation \& Yale University Press, 2015, 280p.

1 La idea de una América continental parece difusa cuando pensamos en términos geopolíticos y nacionales. Este libro no se propone resolver ambigüedades culturales o clausurar conflictos históricos, así como tampoco forzar hermandades ni denunciar hegemonías. Ofrece en cambio una visión panorámica construida sobre la base de una idea fuerte: la representación cultural de la naturaleza -la construcción de paisajes- es un gesto común y de profundo impacto en la historia de la visualidad moderna del continente que, siguiendo la propuesta de los autores, se escribe mejor en plural. La publicación propone, también un ejercicio de autoría colectiva como un modo de preservar la multiplicidad de lenguas y perspectivas, encarnando desde la practica una historia del arte transnacional que no desemboca necesariamente en una historia común, puesto que se plantea desde una escala de estudios de casos. En lugar de un único relato, el libro propone seis ejes o constelaciones en torno a los cuales organiza las numerosas obras reseñadas y las múltiples visiones de los investigadores convocados. Estos ejes dan cuenta de una concepción compleja de paisaje que excede con creces las ideas estéticas de lo pintoresco y lo sublime, puesto que agrega la dimensión científica y económica de estas representaciones, atingentes a un contexto 
atravesado por los procesos de exploración y explotación del territorio, subrayando con ello los alcances político y sociales del género de paisaje.

2 La publicación es el resultado de un proyecto de investigación de largo aliento sobre la presencia de la naturaleza en la cultura visual de las Américas y, particularmente, sobre el género pictórico del paisaje desde comienzos del siglo XIX a comienzos del XX. Un proyecto de esta envergadura solo es concebible como un trabajo colaborativo y así lo llevaron a cabo sus gestores, curadores de tres prestigiosos centros de arte del continente, John Peter Brownlee de la Fundación Terra de Chicago, Valeria Piccoli de la Pinacoteca del Estado de São Paulo, y Georgiana Uhlyarik, de la Galería de Arte de Ontario. El proceso contó con la colaboración de numerosos especialistas de la historia del arte de los diversos países americanos, organizó una serie de encuentros académicos en torno al tema y culminó con la exposición itinerante homónima, inaugurada en la Galería de Arte de Ontario en junio del 2015, coincidiendo con los Juegos Panamericanos, presentada luego en Crystal Bridges Museum of American Art (Arkansas) en el mismo año y finalmente en la Pinacoteca de São Paulo a comienzos del 2016. El libro fue publicado en inglés, castellano y portugués. Es posible además acceder a una exposición virtual (versionada también en francés) desde el sitio: http:// picturingtheamericas.org/themes/?lang=fr

\section{AUTORES}

\section{CATALINA VALDÉS}

doctora en historia del arte, CRAL-EHESS/IDAES-UNSAM

cvaldese@gmail.com 